\title{
Measurement and evaluation of human exposure to vibration transmitted to hand-arm system during leisure cyclist activity
}

\author{
Herbert Martins Gomes*, Daniel Savionek
}

\begin{abstract}
Introduction: The cycling activity has increased in recent years, either as a means of leisure or physical activity or as means of transport. Discomfort is one of the main complaints for cyclists, especially when related to the type o pavement they use while riding. This work presents a study of measurement and evaluation of human exposure to hand-arm vibration in the leisure cyclist activity in different pavements in order to classify according to vibration discomfort and to vibration injury risk. Methods: Vibration measurements are performed for three pavement types, asphalt (AS), precast concrete slab (PC), and interlocking concrete blocks (BI), using two bicycle models (time trial speed racing bike, $\mathrm{S}$ and mountain bike, $\mathrm{MB}$ ), and cyclists with different physical characteristics. It is performed a quantitative analysis of each configuration - pavement type $\times$ bike model $\times$ cyclist - where the daily vibration exposure $A(8)$ is evaluated, as defined in ISO 5349-1 Standard, for $2 \mathrm{~h}$ daily exposure. It is also evaluated the maximum daily exposure in order to reach limit values, as defined by Directive 2002/44/EC. Results: Based on a subjective analysis (survey), it is evaluated the comfort degree for vibration exposure for each tested pavement, according to a survey within cyclists. Finally, the results are compared using both quantitative and subjective analysis. Conclusions: Not surprisingly, it has been noticed that the most comfortable pavement type is the asphalt pavement (AS), followed by the precast concrete pavement (PC) and by the interlocking concrete blocks pavement (BI), confirming the opinion pool within cyclists. As a new finding, for some pavement types, bikes and daily journey activities, the vibration levels may reach health limit levels which justify the originality of the work and the importance as guidance for healthy public decisions for new cycle paths.
\end{abstract}

Keywords Vibration measurement in bicycles, Pavement to cycle paths, Hand-arm vibration, Human exposure to vibration.

\section{Introduction}

The exposure of the human body to vibration is present in everyday situations and may be a source of discomfort and in some cases may cause health problems. Particularly in the case of vibration transmitted to the hand-arm system, disturbances in finger's blood circulation and hand's neurological function injuries may occur. On the other hand, the cycling activity has been increasing in recent years, either as a means of leisure or physical activity or as means of transport and some diseases have been reported by some researchers related to this activity (Capitani and Beer, 2002, Dettori and Norvell, 2006, Patterson et al., 2003). Pivit (1988) reported vibrational stress and probable health effects for riders in typical West Germany cycle tracks. Most of the evaluated paths are made of concrete bricks. They are typical pavements because they are cheap and easily removable for excavation. The cyclists are forced by law to use these cycle paths instead of the smooth asphalt roadway and are subjected to vibration stress. In many situations of old pavements and different bikes, it is reported that according to the German standard, the vibration health limits (G1, G25 L60) are exceeded.
They conclude that the use of improved suspension systems could reduce this vibrational stress.

Some cities have detailed plans for design, construction and management of cycle paths (Coessens, 2011). There are feasibility studies to set up networks of cycling routes, which will allow the displacement of workers from home to a public transport hub or directly to workplace. Currently, the city of Porto Alegre, in Brazil developed a Cycle path Integrated Plan (CIP), by means of a local Complementary Law (Porto Alegre, 2009), which reports a network of $495 \mathrm{~km}$ length of cycling roads to be built. More specifically, some prototype cycle paths that were built with interlocking concrete blocks suffered criticism from cyclists regarding trepidation and discomfort during the cycling activity that deserved more attention and a quantitative evaluation by the government.

Considering the raised points and due to lack of specific studies on the topic, the present work justifies with the overall objective of assessing human exposure to vibration transmitted to the hand-arm during the cycling activity. This study was conducted 
through vibration measurements performed for three different types of paving: asphalt, precast concrete and interlocking concrete blocks, using two bike models and several cyclists with different physical characteristics. The main hypothesis is that there should pavements rated as "good" for the cycling activity that generates the lower vibration in the hand-arm system. The complaints related to vibration from cyclists using a pilot cycle path suggests a high level of HAV that might affect health and a detailed investigation is desirable in order to account for new cycle paths. It is well-known that speed is strongly related to the vibration, so in this investigation the bicycle speed was kept fixed to ordinary mean values of $15 \mathrm{~km} / \mathrm{h}$ referred in the literature (City..., 2013) in order to get a baseline for comparisons.

Moreover, the work has the following specific objectives: (a) Assess if the daily exposure to vibration exceeds the limits set by the Directive 2002/44/EC (European..., 2002) or ISO 5349-1 (International..., 2011), for a given duration of daily exposure to the appropriate cycling activities configurations (type of pavement $\times$ bike's model $\times$ cyclists); (b) Evaluate the maximum daily exposure to vibration for each test, so that the limits specified by the Directive 2002/44/EC (European..., 2002) or ISO 5349-1 (International..., 2011) are met. (c) Evaluate, between types of analyzed paving, which one is most suitable for cycling activity; (d) Evaluate the influence of the bike and the cyclist's physical features on the values of daily exposure to vibration.

\section{Literature review and main concepts}

Generally speaking, a vibration signal can be represented in a graph of vibration amplitude $v s$ time or amplitude of vibration $v$ s frequency (called the frequency spectrum). There are other important parameters that may characterize vibration signals, like frequency $(\mathrm{Hz})$ and amplitude of vibration $\left(\mathrm{m} / \mathrm{s}^{2}\right)$, for instance, the rms (root mean square) value, peak value, peak-to-peak value, mean value, crest factor, etc. (Rasmussen, 1982). Most of international standards related to human exposure to vibration use primarily the rms value as means to characterize the vibration.

\section{Human exposure to vibration}

According to Griffin (1996) the human body, despite its higher complexity, can be considered as a biomechanical system for analysis of vibration. It can be modeled as a multi-degree of freedom system in the frequency range of $1-80 \mathrm{~Hz}$, in the case of whole body vibration. For vibrations of hand-arm system, these frequencies may be higher, reaching up to $1250 \mathrm{~Hz}$. When the frequency of an external excitation reaches the value of one of the natural frequencies of this multi-degree of freedom system, the resonance phenomenon can occur, increasing the effects and risks of vibration on health.

Human exposure to vibration may be classified due to their peculiarities, in (i) Whole Body Vibrations (WBV): vibrations that, as the name suggests, affect the whole body, particularly in a frequency range 0.5 to $80 \mathrm{~Hz}$. This type of vibration may be present in transportation systems, such as buses, cars, trains, etc.; (ii) Hand-Arm vibration (HAV): vibrations that affect and are transmitted specifically to the hand-arm system, in a frequency range from 6.3 to $1250 \mathrm{~Hz}$. This type vibration may be present, for example, in oscillatory hand power-tools like pneumatic hammers and saws. It is also the type of vibration that may be present in cycling activity, whose evaluation is the focus of this work.

It should be noticed that this classification is formal, so one can experience a simultaneous exposure to both types of vibration. A bus driver, for example, may be exposed to whole body vibration on the global movement of the vehicle and also be exposed to vibration of the hand-arm system, from vibrations transmitted by the vehicle's steering system.

\section{Effects on health caused by the exposure to vibration}

Many factors can influence the health effects caused by human exposure to vibration. As an example, one can mention the frequency spectrum and amplitude of vibration, the duration of daily exposure, previous accumulated exposures to vibration. Moreover, certain people may have greater susceptibility to develop some diseases caused by the exposure to vibration. In the case of whole body vibration, the main health effects may present themselves in the form of dizziness, decreased vision acuity, nausea and disorders of the labyrinth, occasioned by vibrations in the frequency range of 0.1 to $0.7 \mathrm{~Hz}$, or effects like increased heartbeat frequency due to vibrations in frequencies below $20 \mathrm{~Hz}$. Also, many studies, such as those of Hoy et al., (2000), Rehn et al. (2000) and Tripepi et al. (2000), indicate that drivers of dump trucks, tractors, forklifts, and other type of off-road vehicles, have a high incidence of back pain, related to exposure to vibration transmitted to the whole body.

According to ISO 5349-1 (International..., 2011), workers exposed to hand-transmitted vibration may complain of episodes of pale or white finger due to temporary abolition of blood circulation to the fingers, that is also called Raynaud's phenomenon or generally known as Vibration induced White-Fingers (VWF). Initially attacks of blanching involve the tips 
of one or more fingers but, with continued exposure to vibration, the blanching can extend to the base of the fingers. During the attack the affected workers can experience a complete loss of touch sensation and manipulative dexterity, which can interfere with work activity, thus increasing the risk for acute injuries due to accidents.

Related to cyclists, there are a lot of diseases that may prevail due to vibration like knee ligaments and meniscus injuries, lower back pain, shoulder pain, calluses and blisters on hands and even erectile dysfunctions. Here, it was not mentioned the many injuries that may occur related to bicycle accidents. In case of vibrations transmitted to the hand-arm system, independent or simultaneously disorders were reported and may occur at the vascular level and at the neurological and muscle-skeletal system. A regular complaint from cyclists is that their hands feel weak, dormant, and sometimes like pinned by needles after long rides as reported by Capitani and Beer (2002) and Patterson et al. (2003). These symptoms often indicate the beginning of a condition known as handlebar palsy, a nerve compression syndrome in the hand caused by bearing weight on the handlebars. Handlebar palsy affects both mountain bike and road cyclists. Recently, Dettori and Norvell (2006) presented studies of the injury's occurrence in long-distance cyclists that show symptoms of nerve compression prevalence as high as $70 \%$. Since the condition of bikers' hand evolves to develop muscle paralysis (the loss of muscle function in the hand) the term palsy has been regularly used as synonym. For a detailed revision on papers related to HAV dose-effect, symptoms and related work the reader is referred to Griffin (1996) and Mansfield (2005).

\section{Methodology of Evaluation according to ISO 5349-1 (International..., 2001) and Directive 2002/44/EC}

The assessment of human exposure to vibration can be performed in accordance with key International Standards ISO (International Organization for Standardization). ISO 2631 (International..., 1997) is concerned with the whole body vibration whereas ISO 5349-1 (International..., 2011) e ISO 5349-2 (International..., 2011) is concerned with the handarm vibration.

In accordance with ISO 5349-1 (International..., 2011 ) the primary variable used to characterize a vibration is the rms acceleration. This rms acceleration should be weighted in frequency domain (weight curve $\mathrm{W}_{\mathrm{h}}$ ) and passed through a narrow band filter, thereby producing a value defined as weighted frequency rms acceleration $\mathrm{a}_{\mathrm{wh}}$ in $\mathrm{m} / \mathrm{s}^{2}$. This weighting indicates the importance that the vibration at different frequencies may affect human body parts. In this curve, there is a high weighting factor (about 1.0) for a frequency range between 4 and $31.5 \mathrm{~Hz}$, which corresponds precisely to the portion where the effects caused by the vibration in hand-arm system may be harmful. Vibrations transmitted to the hand-arm should be measured in three directions, according to an orthogonal coordinate system as defined in ISO 5349-1 (International..., 2011) e ISO 5349-2 (International..., 2011). There are two possible reference systems: the biodynamic and basicentric. However, according to standard practices, the basicentric coordinate system should be adopted. Since the measurement of vibration should be performed following a system of tri-axial coordinates, it is obtained a value of frequency weighted rms acceleration for each axis, $x, y$ and $z$, represented by $a_{\mathrm{hwx}}, a_{\mathrm{hwy}}$ e $a_{\mathrm{hwz}}$ in $\mathrm{m} / \mathrm{s}^{2}$. Following ISO requirements, combining these three values by a vector sum, we obtain the total weighted vibration acceleration $a_{\mathrm{hv}}$ in $\mathrm{m} / \mathrm{s}^{2}$ :

$a_{h v}=\sqrt{{a_{h w x}{ }^{2}+a_{h w y}{ }^{2}+a_{h w z}{ }^{2}}^{2}}$

Besides the magnitude of vibration, represented by the total weighted vibration $a_{\mathrm{hv}}$, the assessment of vibration exposure takes into account the daily duration of exposure $T$, in hours, defined as the amount of time that the hands are exposed to the vibration in one day. Thus, it is defined the daily exposure to vibration $A(8)$ in $\mathrm{m} / \mathrm{s}^{2}$, as:

$$
A(8)=a_{h v} \sqrt{T / T_{0}}
$$

where $T_{0}$ is referred to eight hours of exposure. This reference time $T_{0}$ is adopted to ease comparisons between daily exposures of different durations. The daily exposure to vibration $A(8)$ is interpreted as a total vibration value weighted by the frequency, expressed as an equivalent value for eight hours of exposure.

\section{Limits for human exposure to vibration}

Due to various effects caused by the human body and the degree of severity that they can reach, exposure to vibration is the subject of legislation on health and safety at work. In Brazil, the Regulatory Standard No. 15 (Brasil, 2002) defines that activities and operations that expose workers without adequate protection to localized or whole body vibration, will be characterized as unhealthy. Following this Standard, the expertise judgment should be based on the exposure limits set by the ISO 2631 and ISO 5349 standards or their substitutes. However, in case of exposure to vibration transmitted to the hand-arm system, the ISO 5349-1 (International..., 2011) says that it does not define 
precise safety limits for exposure to vibration, but rather, only provides a guide to assess the severity of exposure and the percent number of works that might present some health effects (Figure 1(b)). This shows sometimes confusing for interpretation and has caused some doubt in the application of the standard. For sake of comparison, corresponding to $8 \mathrm{~h}$ daily exposure, a limit of $3.7 \mathrm{~m} / \mathrm{s}^{2}$ is established and a prevalence of $10 \%$ of VWF in the exposed population is expected.

Moreover, the European Union established a directive 2002/44/EC (European..., 2002) requiring their member countries to implement in their legislation the minimum health and safety requirements, on exposure of workers to risks arising from physical agents, for instance, vibration. In the case of vibration transmitted to the hand-arm system, unlike ISO 53491:2011, the requirements are well established by two reference values: (a) Exposure Action Value (EAV) of $2.5 \mathrm{~m} / \mathrm{s}^{2}$ and (b) Exposure Limit Value (ELV) of $5.0 \mathrm{~m} / \mathrm{s}^{2}$. These benchmarks correspond to the daily vibration exposure $A(8)$, established in accordance with the methodology of assessment of exposure to vibration in ISO 5349-1 (International..., 2011) and calculated according to Equation 2. So these values limits may be used instead the statistics assessment curve defined by ISO 5249-1 (International..., 2001). Figure 1(a) shows a graph for acceptable total vibration $a_{\mathrm{hv}} v s$ acceptable daily exposure time $T$, with curves representing the daily exposure to vibration $A(8)$ following directive 2002/44/EC definitions.

The graph in Figure 1(a) represents the way to calculate the daily exposure to vibration $A(8)$, for data values of $a_{\mathrm{hv}}$ and total vibration exposure time $T$. For instance, for a daily exposure of $T=4 \mathrm{~h} 30 \mathrm{~min}$ and a total vibration $a_{\mathrm{hv}}$ of $4 \mathrm{~m} / \mathrm{s}^{2}$ it indicates a daily exposure to vibration $A(8)$ of $3 \mathrm{~m} / \mathrm{s}^{2}$. This value is above the exposure action value of $2.5 \mathrm{~m} / \mathrm{s}^{2}$. According to the Directive 2002/44/EC (European..., 2002) this is above the "exposure action value" and requires the employer to implement programs aiming the reduction or elimination of the exposure. Besides, a vibration level above the "exposure limit value" requires the immediate measures for vibration reduction and the employee is not allowed to work in this situation. There may be a risk of hand-arm vibration injury for exposures even below the EAV, and thus some exposures within the green area (Figure 1(a)) may
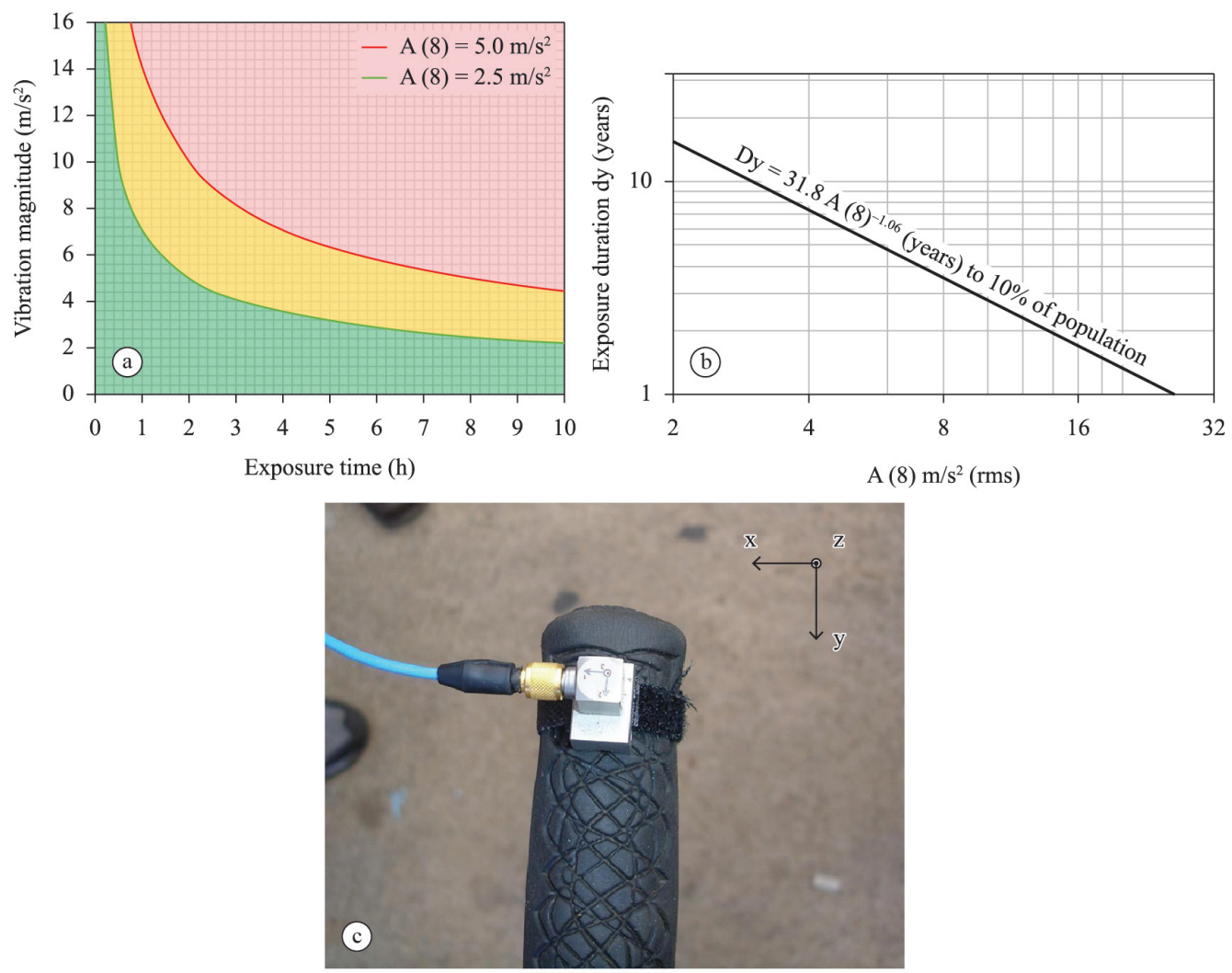

Figure 1. (a) Vibration $a_{\mathrm{hv}} \times$ total daily exposure time $T$, with curves representing the daily exposure to vibration $A(8)$ (Griffin et al., 2006); (b) Exposure durations and daily equivalent vibration for HAV to $10 \%$ of the population develop Vibration induced White-Fingers VWF (ISO 5349-1, 2011); (c) Fixing the accelerometer to the handlebar assigned coordinate system. 
cause vibration injury in some workers, especially after many years of exposure.

Using Figure 1(b), according to ISO 5349-1 (International..., 2011), the same daily exposure $\left(A(8)=3 \mathrm{~m} / \mathrm{s}^{2}\right)$ will cause a $10 \%$ prevalence of VWF in a population exposed to this vibration only if this daily exposure remains for approximately 3 years.

\section{Methods}

The assessment of the exposure to vibration transmitted to the hand-arm during the cycling activity consisted of quantitative evaluation, following the methodology described by ISO 5349-1 (International..., 2011) and an opinion pool within cyclists. The acceleration was measured close to cyclist's hand attaching an accelerometer to the handlebar (Figure 1(c)). It was also measured for three different types of paving: asphalt (AS), precast concrete slab (PC) and interlocking concrete blocks (BI), using two models of bicycle: time trial speed racing (S) and mountain bike (MB), and seven cyclists with different physical features. There is a measurement for each of the combination - the type of pavement $x$ bike model $x$ cyclist - on a linear path of 500 meters of each paving, at an average speed standard of $15 \mathrm{~km} / \mathrm{h}$ measured with the bike's speedometer and controlled by the cyclist.

\section{Measuring equipment}

In the performed measurements, the transducer used is a calibrated tri-axial piezoelectric accelerometer Dytran, Model 3023A2, S/N4147, with nominal sensitivity of $10 \mathrm{mV} / \mathrm{g}$ for each of its axes $x, y$ and $z$. in addition to the transducer, it is necessary to use a device to analyze and store the acceleration measurements. It was used the Quest VI-400Pro (Quest..., 2005), S/N12430, a portable vibration analyzer that simultaneously measures the triaxial vibrations from the accelerometer. The equipment conforms to ISO 8041 (International..., 2005), European Vibration Directive 2002/44/EC (European..., 2002) and the corresponding IEC and ANSI standards for Type 1 equipment. The uncertainty using Type 1 equipment may vary depending on the frequency range according to ISO 8041 (International..., 2005) but is larger at the vicinity of the frequency band and for Type 1 instruments, not greater than $\pm 0.7 \mathrm{~dB}(8.3 \%)$.

Among the parameters of the measured vibration signal, there is the value of frequency weighted rms acceleration for each axis $\left(a_{\mathrm{hwx}}, a_{\mathrm{hwy},} a_{\mathrm{hwz}}\right)$ and $a_{\mathrm{hv}}$ the total exposure to vibration and the extrapolated daily exposure to vibration $A(8)$, as defined by ISO 5349-1 (2011). It was set up the QuestSuite Professional II software for analysis using the frequency-weighting curve $W_{\mathrm{h}}$, as recommended by the ISO standard.

\section{Bike set up instrumentation}

The bike instrumentation is performed fixing the accelerometer on its handlebars so that it is rigidly attached to the structure. The positioning of the accelerometer was carefully checked to assure consistent measurements with hand position. In addition to the correct alignment of the axes of the accelerometer, it needs to be positioned at the point closest to the hand grip on the handlebars, but without interfering in the normal cycling activity. Figure 1(b) shows a picture for the fixing of the accelerometer to the handlebars of the bicycle, along with the adopted coordinate system.

\section{Types of rated pavements}

The AS paving is considered as a flexible type and characterized by a relatively smooth and uninterrupted rolling surface. The measurements in this type of pavement were performed on the right side of the Daily News Avenue, in Porto Alegre, Brazil. The PC paving is considered as a rigid type and characterized by a rolling surface with some interruptions due to the joints between the slabs. In the case evaluated, the slabs have dimensions of $2 \mathrm{~m}$ wide by $6 \mathrm{~m}$ long, with joints every $6 \mathrm{~m}$ in length of the track. Measurements on this type of pavement were held at Érico Veríssimo Avenue in Porto Alegre, Brazil. At last, the $\mathrm{BI}$ pavement is also considered a rigid type, but characterized by a rolling surface with periodic interruptions, due to the joints between the interlocking concrete blocks. In the evaluated case, the blocks have dimensions of $10 \mathrm{~cm}$ wide by $20 \mathrm{~cm}$ long and were paved transversely to the direction of the bike path; with joints at every 10 $\mathrm{cm}$. Measurements on this type of pavement were held in the cycle way beside the Eduardo Schann Avenue, in Porto Alegre, Brazil. Figure 2 shows pictures for the three evaluated types of pavements.

\section{Types of bicycles used}

Measurements were performed using two types of bicycles, speed racing bike (S) and mountain bike (MB). The main features of each model are shown in Table 1. The main differences between each bike model relate the frame shape, tire calibration and tire width. The MB model is $3.3 \mathrm{~kg}$ heavier than the $\mathrm{S}$ model and has a tire width more than twice the $\mathrm{S}$ model and a tire pressure considerably lower. None of the bikes has absorbers, since this type of bike is not so common on weekend cyclists. 

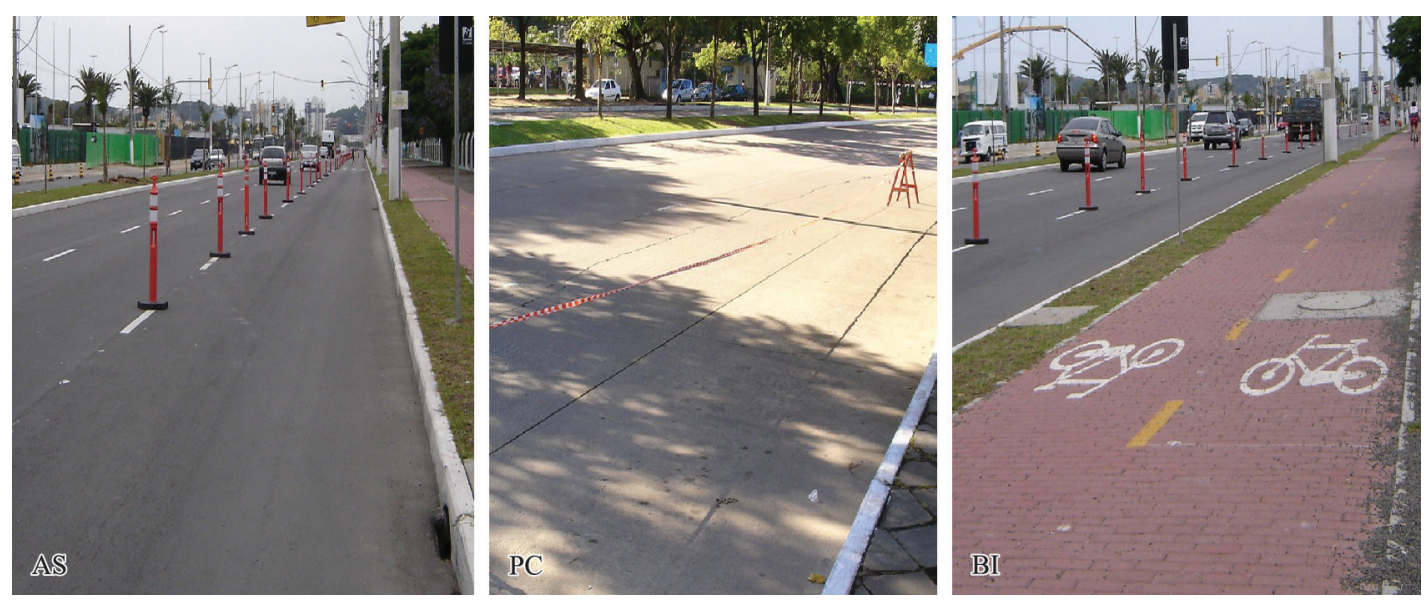

Figure 2. Types of pavements used in measurements: Asphalt (AS), precast concrete slabs (PC) and interlocking concrete blocks (BI).

Table 1. Bicycle's features: speed racing (S) and mountain bike (MB).

\begin{tabular}{lcc}
\hline Feature / Model & $\begin{array}{c}\text { Speed racing } \\
\text { bike (S) }\end{array}$ & $\begin{array}{c}\text { Mountain bike } \\
\text { (MB) }\end{array}$ \\
\hline Frame & $\begin{array}{c}\text { carbon fiber and } \\
\text { aluminum }\end{array}$ & aluminum \\
Mass & $8.7 \mathrm{~kg}$ & $12 \mathrm{~kg}$ \\
Frame height & $53 \mathrm{~cm}$ & $45.7 \mathrm{~cm}$ \\
Wheelbase & $98 \mathrm{~cm}$ & $108 \mathrm{~cm}$ \\
Tire dimensions & $700 \times 23 \mathrm{~mm}$ slick & $660.4 \times 49.5 \mathrm{~mm}$ \\
(Diameter x width) & & knobby \\
Tire pressure & $110 \mathrm{psi}$ & $45 \mathrm{psi}$ \\
Handlebars type & dropped $44 \mathrm{~cm}$ & straight $58 \mathrm{~cm}$ \\
\hline
\end{tabular}

\section{Characterization of cyclists}

Measurements in the three types of pavements and with the two bike models were conducted with seven cyclists. However, two of the cyclists were not involved in the measurements of PC pavement. This totals 38 measurements. Table 2 presents the main characteristics of each cyclist. They were ordered in descending order of mass.

\section{Subjective evaluation of vibration in the cyclist activity}

The subjective evaluation of human exposure to vibration consisted in opinion pool that tries to capture the perception of tested cyclists related to conditions of comfort offered by each type of pavement. At the end of each measurement a questionnaire was given to the cyclist, where he/she was asked to give a score on a 0-5 scale, according to the degree of perceived comfort. The scores correspond to concepts, ranging from very bad (0-1), bad (from 1.1 to 2), regular (from 2.1 to 3 ), good (from 3.1 to 4 ) to very good (from 4,1 to 5). Moreover, the biker was asked to give their opinion about the quality of the ride, with the following possible alternatives: "acceptable," "unacceptable" and "undecided."
Table 2. Cyclist's features.

\begin{tabular}{cccccc}
\hline Id & Gender & $\begin{array}{c}\text { Age } \\
(\text { years })\end{array}$ & $\begin{array}{c}\text { Mass } \\
(\mathbf{k g})\end{array}$ & $\begin{array}{c}\text { Height } \\
(\mathbf{m})\end{array}$ & $\begin{array}{c}\text { Body } \\
\text { Mass } \\
\text { Index }\end{array}$ \\
\hline A & M & 28 & 89 & 1.86 & 25.73 \\
B & M & 36 & 81 & 1.74 & 26.75 \\
C & M & 31 & 80 & 1.82 & 24.15 \\
D & M & 50 & 73 & 1.63 & 27.48 \\
E & F & 29 & 68 & 1.64 & 25.28 \\
F & F & 28 & 61 & 1.75 & 19.92 \\
G & M & 36 & 59 & 1.72 & 19.94 \\
Mean & & 34.0 & 73.0 & 1.7 & 24.2 \\
Std. dev. & & 7.85 & 11.06 & 0.08 & 3.09 \\
\hline
\end{tabular}

\section{Results}

\section{Quantitative evaluation of vibration in cyclist activity}

As explained, using the total weighted vibration $a_{\mathrm{hv}}$ ' the daily exposure to vibration $A(8)$ is estimated, according to Equation (2). However, this calculation requires the assumption of the exposure time $T$. This is a difficult parameter to be estimated for the cycling activity, since the days one can practice this activity can vary from biker to biker. We decided to examine the daily exposure to vibration $A(8)$ for a daily duration of exposure $T=2 \mathrm{~h}$, representing an average exposure time for leisure purposes. Figure 3 shows a graph for the daily exposure to vibration $A(8)$ for $T=2 \mathrm{~h}$, for the three evaluated pavements.

Each point on the graph represents the mean value of measurements of a combination (cyclist, pavement, and bicycle). In the $\mathrm{x}$-axis the cyclists are listed and in the $y$-axis, the corresponding mean daily vibration exposure $A(8)$ are presented. The vertical line in the middle of the graph indicates the division 
between measurements made with the mountain bike (MB) and the speed racing (S) bicycle. Bars on the right indicate the arithmetic mean of daily exposure to vibration $A(8)$ for $\mathrm{AS}, \mathrm{PC}$, and $\mathrm{BI}$ pavements. The horizontal lines represent the exposure action limit (EAV) and exposure limit value (ELV) according to Directive 2002/44/EC (European..., 2002).

From Figure 3, one can get a general idea of the exposure to vibration in each type of pavement. AS has the lowest accelerations, with all ratings (pavement and cyclist) below the exposure action limit (EAV) and with an average daily exposure to vibration $A(8)$ of $1.24 \mathrm{~m} / \mathrm{s}^{2}(\mathrm{CV}=1,3 \%)$. PC has relatively higher values for vibration, including some values above the exposure action limit (EAV) and with an average daily exposure to vibration $A(8)$ of $1.92 \mathrm{~m} /$

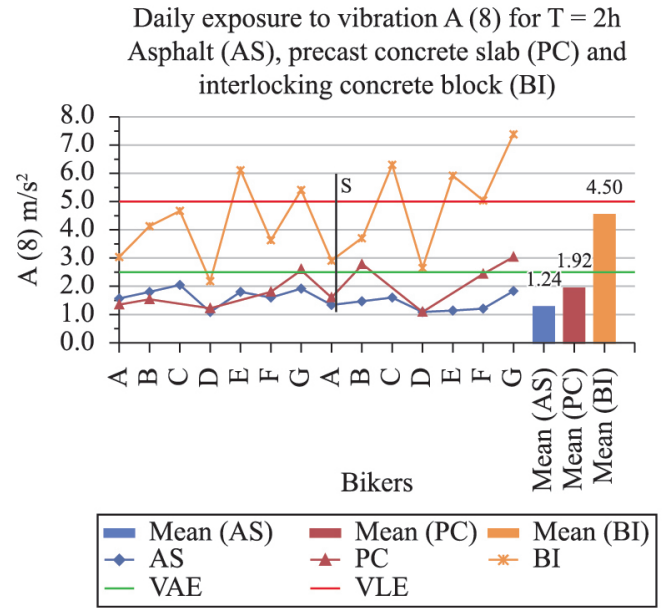

Figure 3. Daily exposure to vibration $A(8)$ with a daily duration of exposure of $T=2 \mathrm{~h}$, for the three types of pavements evaluated.
$\mathrm{s}^{2}(\mathrm{CV}=2,2 \%)$. BI presents exposures that reach values considerably larger in majority of measurements (except one, above the exposure action limit (EAV) and some exposures above the exposure limit value (ELV). The average daily exposure to vibration $A(8)$ for this pavement is $4.5 \mathrm{~m} / \mathrm{s}^{2}(\mathrm{CV}=3,3 \%)$. The lower dispersion of the data, represented by the coefficient of variation $(\mathrm{CV})$ is within the same order of magnitude for all pavements and allows direct comparisons between mean values. According to ISO 5349-1 (International..., 2011), it would take 25 years, 16 years and 6.4 years of exposure to vibration in the $\mathrm{AS}, \mathrm{PC}$ and BI pavements, respectively, so $10 \%$ of a population of exposed cyclists to develop VWF. This information sounds a little vague, since no one knows how long the cycling activity will be part of the physical activity of a person, however it make possible to rate the level of exposition to HAV.

Thus, one can sort the types of pavements, as to $A(8)$, so that AS is the most suitable surface for cycling activity, followed by PC and BI. To evaluate a possible influence of the bike on these values, it was generated independent graphs, showing $A(8)$, for each type of pavement, as can be seen in Figure 4 and Figure 5. For AS pavement, as indicated by the graph in Figure 4(a), the ratings with the speed racing bicycle (S) resulted values of $A(8)$ slightly smaller, with an average acceleration of $1.12 \mathrm{~m} / \mathrm{s}^{2}(\mathrm{CV}=1,1 \%)$ against $1.37 \mathrm{~m} / \mathrm{s}^{2}(\mathrm{CV}=2,3 \%)$ with the MB bicycle. The average daily exposure to vibration $A(8)$ for AS pavement, considering the ratings for the two models of bike is $1.24 \mathrm{~m} / \mathrm{s}^{2}(\mathrm{CV}=1,7 \%)$, as indicated by the third bar graph in the same Figure.

The situation is reversed for the PC pavement, as indicated by the graph in Figure 4(b), i.e., the

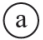

Daily exposure to vibration $A(8)$ for $T=2 h$ Asphalt (AS)

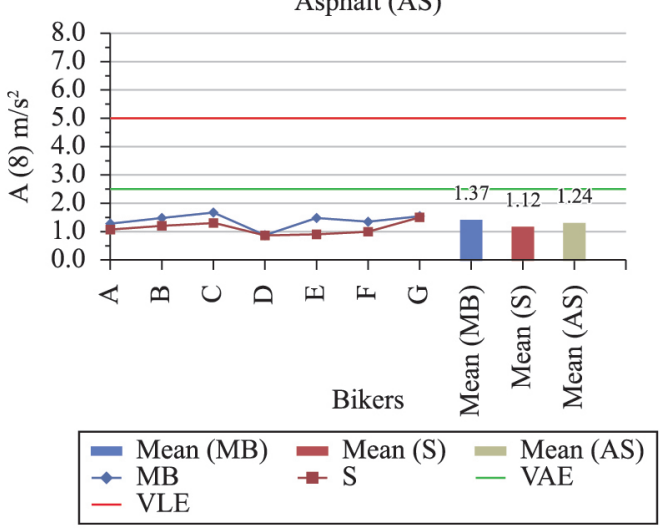

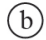

Daily exposure to vibration $\mathrm{A}(8)$ for $\mathrm{T}=2 \mathrm{~h}$ Precast concrete slab (PC)

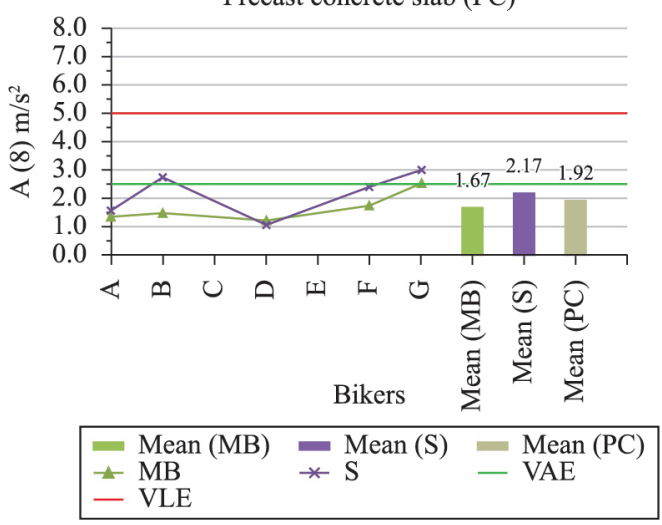

Figure 4. (a) Daily exposure to vibration $A(8)$ with a daily duration of exposure of $\mathrm{T}=2 \mathrm{~h}$, for the asphalt pavement (AS); (b) Daily exposure to vibration $A(8)$ with a daily duration of exposure $\mathrm{T}=2 \mathrm{~h}$, for precast concrete slabs cast on site concrete (PC). 
measurements with the speed racing bicycle $(\mathrm{S})$ showed $A(8)$ values slightly higher.

Finally, for the BI pavement the ratings had a third behavior, with some lower values of $A(8)$ for bike $\mathrm{S}$ and smaller ones for $\mathrm{MB}$, as shown in the graph in Figure 5(a). It was expected, mainly due to differences in tire width and tire pressure, that the mountain bike model (MB) have a greater damping behavior, resulting in lower $A(8)$. However, this was not confirmed by the results.

Moreover, it can be said that for most measurements (comparing the two bike models), even for the same cyclist and same pavement, there was a significant difference $(\mathrm{p}=0.06)$ between the values of $A(8)$.

From the graphs presented in Figures 4 and 5 one can also analyze a possible influence of the physical characteristics of cyclists on the values of $A(8)$. Remembering that cyclists are sorted in descending order of masses, the graphs in Figures 4 and 5 do not present any pattern of behavior in $A(8)$ values. For instance, although the D cyclist has a value of intermediate mass in relation to other cyclists, in all tests he/she presented the lowest daily exposure to vibration $A(8)$. So, it was not possible to say that the mass of the cyclist significantly influences $A(8)$ values $(p=0.02)$.

In the measured samples, the estimated average speed value for a traveled distance of $500 \mathrm{~m}$ was $V_{\text {med }}$ was $14.1 \mathrm{~km} / \mathrm{h}(\mathrm{CV}=10 \%)$. This value was very close to that asked to the cyclists to maintain based on readings in the installed speedometer $(15 \mathrm{~km} / \mathrm{h})$ and represents a usual velocity in leisure activities (City..., 2013) and was kept constant for this study in order to validate the comparisons.

When analyzing the average speeds developed by cyclist $\mathrm{D}$, one can identify that for most of measurements, except for PC pavement with the mountain bike (MB), the values were below the overall average speed of $14.1 \mathrm{~km} / \mathrm{h}$. This fact may explain lower values of daily vibration exposure $A(8)$, compared to the values of other cyclists, since riding speed is strongly related to vibration magnitude.

From another point of view, one can use the amount of daily exposure vibration $A(8)$ in equation (2) as the vibration exposure action value (EAV) or the vibration exposure limit value (ELV) to calculate the maximum daily exposure time in order to achieve those vibration values, $T_{\operatorname{maxEAV}}$ and $T_{\operatorname{maxELV}}$, respectively. Figure 5(b) shows $T_{\operatorname{maxEAV}}$ for the pavements evaluated. Exposure times greater than $8 \mathrm{~h}$ are shown for convenience as $8 \mathrm{~h}$.

In Figure 5(b), the highest maxima exposure times to vibration in order to reach EAV, $T_{\operatorname{maxEAV}}$, were found for AS pavement (7h), followed by PC pavement (4.46h) and by BI pavement $(0.91 \mathrm{~h})$. For BI pavement, the average value $T_{\text {maxEAV }}=0.91 \mathrm{~h}(55$ min.) represents the allowable time to a low energy cycling activity. In some measurements $T_{\operatorname{maxEAV}}$ resulted close to or less than $30 \mathrm{~min}$.

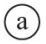

Daily exposure to vibration $\mathrm{A}(8)$ for $\mathrm{T}=2 \mathrm{~h}$ Interlocking concrete (BI)

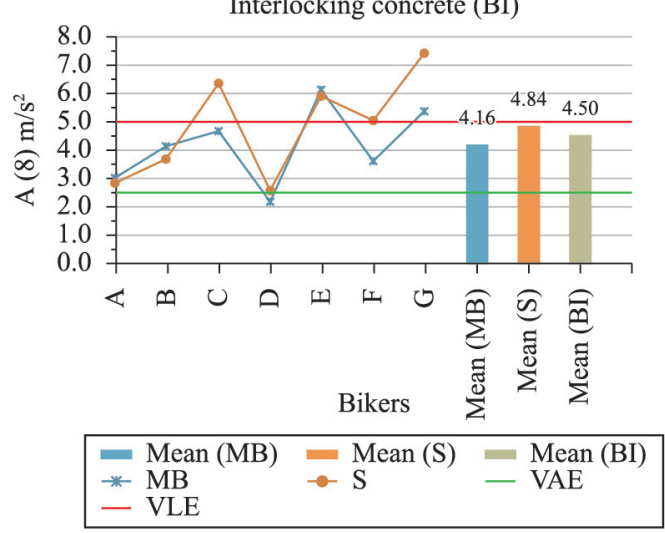

(b)

Maximum exposure time to vibration to reach VAE Asphalt (AS), precast concrete slab (PC) and interlocking concrete blocks (BI)

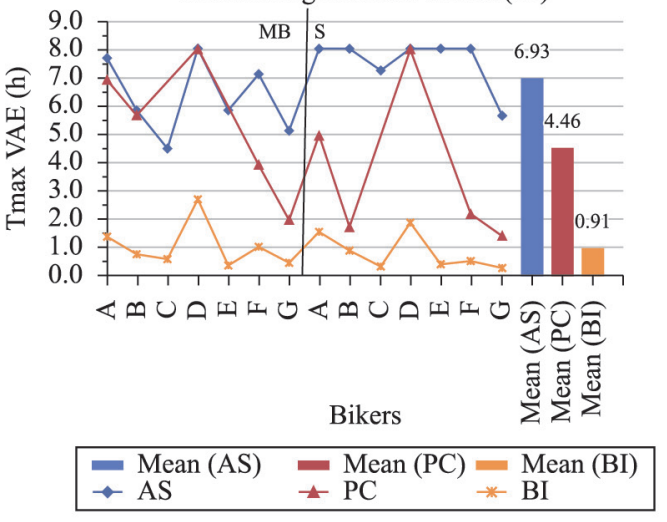

Figure 5. (a) Daily exposure to vibration $A(8)$ with a daily duration of exposure of $T=2 \mathrm{~h}$, for interlocking concrete block(BI); (b) Maximum exposure time to reach EAV. 


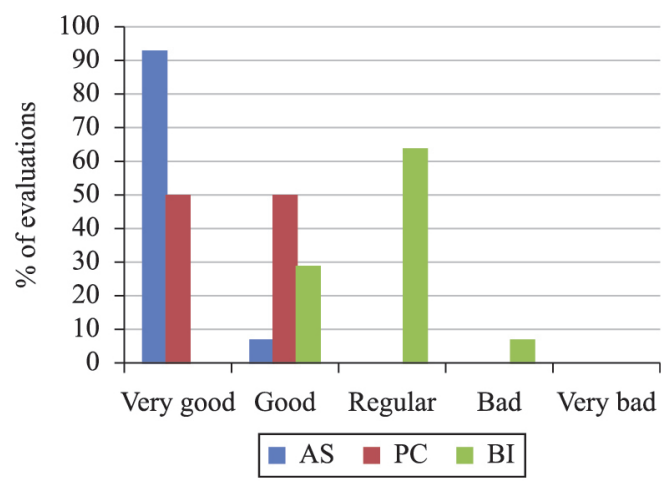

Figure 6. Assigned scores for rated pavements.

\section{Subjective evaluation of vibration in cyclist activity}

Figure 6 shows the scores assigned by cyclists for each type of pavements evaluated.

As indicated by Figure 6 for the AS pavement, more than $90 \%$ of the assigned concepts were "very good", with the remainder "good". For PC pavement, the attributed concepts were equally divided between "very good" and "good". Finally, for BI pavement, the assigned concepts were divided between "good", with $29 \%$, "regular", with $64 \%$ of ratings, and "bad", with $7 \%$ of cases. This emphasizes and corroborates the results already presented taking the acceleration as baseline.

Related to the cyclist opinion to the quality of the ride, most of the opinions were for "acceptable," except for one "undecided" and one for "unacceptable" for BI pavements. An ANOVA analysis revealed a strong correlation between the opinion pool and the measured acceleration $\left(\mathrm{R}^{2}=0.88, \mathrm{p}=0.02\right)$.

Thus, in cyclist's subjective evaluation, one can sort the types of pavements by degree of comfort, being AS the pavement most preferable for cycling activity, followed by PC and BI. This classification matches with the previous classification obtained by the quantitative evaluation.

\section{Discussion}

According to the quantitative assessment of human exposure to vibration transmitted to the hand-arm system, depending on exposure conditions, this phenomenon may be important in this cycling activity, so the maintenance of daily exposure to vibration $A(8)$ within limits established by 2002/44/EC Directive is crucial to ensure health for cyclists even in leisure activities.
For a daily exposure duration of $\mathrm{T}=2 \mathrm{~h}$, the evaluations for AS pavement showed the lowest $A(8)$ values $\left(1.24 \mathrm{~m} / \mathrm{s}^{2} \mathrm{CV}=1,3 \%\right)$ with all values below the vibration exposure action (EAV, Directive 2002/44/EC). PC pavements presented relatively higher $A(8)$ values $\left(1.92 \mathrm{~m} / \mathrm{s}^{2}, \mathrm{CV}=2,2 \%\right)$, including some values above the vibration exposure action (EAV). BI pavements measurements indicated higher values $\left(4.5 \mathrm{~m} / \mathrm{s}^{2}\right.$, $\mathrm{CV}=3,3 \%$ ), with majority of measurements, except one, above the vibration exposure action (EAV) and some acceleration values above the exposure limit value (ELV). According to ISO 5349-1 (International..., 2011), it would take 25 years, 16 years and 6.4 years of exposure to vibration in the AS, PC and BI pavements, respectively, so $10 \%$ of a population of exposed cyclists to develop VWF.

Regarding the influence of the bike type in $A(8)$ values, sometimes the speed racing (S) showed better performance (lower accelerations) and sometimes mountain bike (MB) presented better results. But in general, there was not a significant correlation between $A(8)$ values and the two bike models $(\mathrm{p}=0.06)$.

An ANOVA revealed a strong correlation between the opinion pool and the measured acceleration $\left(\mathrm{R}^{2}=0.88, \mathrm{p}=0.02\right)$ that confirms the previous conclusion and pavement ranking related to comfort.

Regarding the analysis of the maximum daily exposure to vibration in order to achieve the vibration exposure action $T_{\operatorname{maxEAV}}$, the largest allowable time were found for AS pavement, followed by PC and BI pavements. This last pavement type presented an average $T_{\text {maxEAV }}$ less than $1 \mathrm{~h}$, with some measured values close to $30 \mathrm{~min}$. This indicates some concerns about leisure activities in this type of paving using any of the bicycles measured and almost all cyclists.

Regarding the influence of the physical characteristics of cyclists on $A(8)$, particularly in relation to their masses, it was not possible to identify a pattern of behavior for the $\mathrm{A}(8)$ values due to the large variability and lack of correlation in the data $(p=0.3)$.

In conclusion, it can be said that the AS pavement is the most suitable for the cycling activity followed PC and BI pavement. Concerns related the health effects in cycling activity in the last BI pavement, for any type of bicycle for a daily exposure greater than $1 \mathrm{~h}$ are highlighted. Similar findings, relate to health effects in typical West Germany cycle tracks, are reported by Pivit (1988) that suggests the track roughness as the main cause of the vibration stress. They imply that the use of improved suspension system may reduce this vibrational stress in the case of bumpy paths. 


\section{Acknowledgements}

The authors acknowledge the support of Brazilian Councils CNPq and CAPES in this research.

\section{References}

Brasil. Ministério do Trabalho e Emprego. Regulatory Standard no 15: Annex $n^{\circ}$ 8. NR15 Unhealthy activities and operations: vibrations [internet] 2002 [cited 2014 Jul 1]. (Portuguese). Available from: http://www.mte.gov. br/legislacao

Capitani D, Beer S. Handlebar Palsy: a compression syndrome of the deep terminal (motor) branch of the ulnar nerve in biking. Journal of Neurology. 2002; 249(10):1441-5. PMid:12382163. http://dx.doi.org/10.1007/s00415-0020864-4

City of Copenhagen. Bicycle statistics. Copenhagen: Traffic Department [internet] 2013 [cited 2013 Jun 13]. Available from: https://subsite.kk.dk/sitecore/content/Subsites/ CityOfCopenhagen/SubsiteFrontpage/LivingInCopenhagen/ CityAndTraffic/CityOfCyclists/CycleStatistics.aspx.

Coessens B. Bicycles measure the quality of cycle paths in Belgium. ELTIS the Urban Mobility Portal [internet] 2011 [cited 2014 Jan 1]. Available from: http://www.eltis.org/ index.php?id=13\&study_id=3168.

Dettori NJ, Norvell DC. Non-traumatic bicycle injuries: a review of the literature. Sports Medicine. 2006; 36(1):7-18.

European Agency for Safety and Health at Work. Directive 2002/44/EC. On the minimum health and safety requirements regarding the exposure of workers to the risks arising from physical agents (vibration). Official Journal of the European Communities, 2002. Available from: https://osha.europa. eu/en/legislation/directives/exposure-to-physical-hazards/ index_html.

Griffin MJ. Handbook of human vibration. New York: Academic Press; 1996.

Griffin MJ, Howarth HVC, Pitts PM, Fischer S, Kaulbars U, Donati PM, Bereton PF. Guide to good practice on handarm vibration [internet] 2006 [cited 2014 Jan 1]. Available from: http://resource.isvr.soton.ac.uk/hrv/vibguide.htm.

Hoy J, Mubarak N, Nelson S, Magnusson M, Sweerts de Landas M, Pope M. The effect of whole body vibration on forklift drivers. In: Proceedings of 2nd International Conference on Whole-Body Vibration Injuries; 2000 Nov 7-9; Siena, Italy. p. 20-1. PMid:21946455
International Organization for Standardization - ISO. ISO 2631-1. Mechanical vibration and shock: evaluation of human exposure to whole body vibration. Part 1: general requirements. Switzerland [internet]. 1997 [cited 2014 Jan 1]. Available from: http://www.iso.org/iso/catalogue_detail. htm? csnumber $=7612$.

International Organization for Standardization - ISO. ISO 5349-1. Mechanical vibration: measurement and evaluation of human exposure to hand-transmitted vibration. Part 1: general requirements. Switzerland [internet]. 2011 [cited 2014 Jan 1]. Available from: http://www.iso.org/iso/home/ store/catalogue_tc/catalogue_detail.htm?csnumber $=32355$.

International Organization for Standardization - ISO. ISO 5349-2. Mechanical vibration: measurement and evaluation of human exposure to hand-transmitted vibration. Part 2: practical guidance for measurement at the workplace. Switzerland [internet]. 2011 [cited 2014 Jan 1]. Available from: http://www.iso.org/iso/catalogue_detail. htm? csnumber $=27511$.

International Organization for Standardization - ISO. ISO 8041: human response to vibration: measuring instrumentation. Switzerland [internet]. 2005 [cited 2014 Jan 1]. Available from: http://www.iso.org/iso/catalogue detail. htm? csnumber $=30145$.

Mansfield NJ. Human response to vibration. Boca Raton: CRC Press; 2005.

Patterson JM, Jaggars MM, Boyer MI. Ulnar and median nerve palsy in long-distance cyclists. The American Journal of Sports Medicine. 2003; 31(4):585-9. PMid:12860549

Pivit R. Vibration stress on cyclists. Human Power, 1988; $7(2): 4-2$.

Porto Alegre. Lei Complementar $n^{\circ} 626$, de 15 de julho de 2009. Institui o Plano Diretor Cicloviário Integrado e dá outras providências. Diário Oficial de Porto Alegre, Porto Alegre, jun. 2009. Disponível em: http://www.camarapoa. rs.gov.br/biblioteca/integrais/LC\%20626.pdf.

Quest Technologies. VI-400PRO: real-time vibration analyzer. Preliminary owner's manual [internet] 2005 [cited 2014 Jan 1]. Available from: http://multimedia.3m. $\mathrm{com} / \mathrm{mws} /$ mediawebserver?mwsId=SSSSSuH8gc7nZxtUo 82vm8 eevUqe17zHvTSevTSeSSSSSS--\&fn=VI400Pro Manual.revision_a_2005.

Rasmussen G. Human body vibration exposure and its measurements. Technical Review. 1982; (1):3-29.

Tripepi MG, Cantio M, Saffioti G. Risk and effects of WBV in locomotive engineers. Proceedings of the 2nd International Conference on Whole-Body Vibration Injuries; 2000; Siena, Italy. p. 27-8.

\section{Authors}

Herbert Martins Gomes*, Daniel Savionek

Federal University of Rio Grande do Sul - UFRGS, Av. Sarmento Leite, 425, $2^{\circ}$ andar, CEP 90050-170, Porto Alegre, RS, Brasil. 